\title{
Comunicação
}

[Communication]

\section{Determinação das atividades séricas de creatina quinase, lactato desidrogenase e aspartato aminotransferase em eqüinos de diferentes categorias de atividade}

\author{
[Determination of serum activities of creatine kinase, lactate dehydrogenase, and aspartate aminotransferase in \\ horses of different activities classes]
}

\author{
I.A. Câmara e Silva ${ }^{1}$, R.V.C. Dias $^{2}$, B. Soto-Blanco ${ }^{2 *}$ \\ ${ }^{1}$ Médica Veterinária - autônoma \\ ${ }^{2}$ Departamento de Ciências Animais - UFERSA \\ Caixa Postal 147, \\ 59625-900, Mossoró, RN
}

As lesões da musculatura esquelética são freqüentemente encontradas na clínica de eqüinos. Os sinais clínicos presentes em distintas alterações musculares são semelhantes e bastante inespecíficos; por isso, quando isolados, têm limitado valor diagnóstico, requerendo, freqüentemente, o uso de exames laboratoriais complementares (Beech, 2000a,b). O exame complementar mais utilizado em medicina eqüina é a bioquímica sérica para determinação das enzimas de função muscular (Harris et al., 1998; Cardinet III, 1997). As principais enzimas avaliadas são a creatina fosfoquinase (CK), lactato desidrogenase (LDH) e aspartato aminotransferase (AST), e suas atividades séricas aumentam quando ocorre lesão muscular esquelética e cardíaca (Duncan e Prasse, 1986; Cardinet III, 1997).

A CK catalisa a fosforilação da adenosina difosfato (ADP) do fosfato de creatina, tornando o adenosina trifosfato (ATP) disponível para a contração muscular. A LDH, que catalisa a reação reversível de L-lactato para piruvato em todos os tecidos, está presente em grandes quantidades na musculatura esquelética, mas o aumento da atividade sérica desta enzima não é específico para lesão muscular. A AST, que catalisa a transaminação de L-aspartato e alfacetoglutarato em oxalacetato e glutamato, é encontrada em quase todos os tecidos, logo, a atividade sérica de AST não é específica para nenhum tecido, mas o músculo e o fígado podem ser considerados as maiores fontes. Assim, a melhor forma de avaliar bioquimicamente a função muscular esquelética é por meio da determinação da atividade das três enzimas (Duncan e Prasse, 1986; Cardinet III, 1997).

Entretanto, foi verificada a ocorrência de alterações nas atividades séricas das enzimas de origem muscular em resposta ao treinamento e exercícios, o que teria grande importância e interesse na clínica eqüina (Rose et al., 1983; Duncan e Prasse, 1986; Freestone et al., 1989; Cardinet III, 1997; Harris et al., 1998). De fato, a permeabilidade do sarcolema aumenta durante o exercício, e a CK e AST podem escoar para o plasma (Valberg, 1996). Quando o período de duração do exercício é mantido constante, a intensidade do exercício determina o aumento na concentração de CK (Harris et al., 1998). Por outro lado, um programa de treinamento adequado, que se ajusta ao condicionamento físico do eqüino, não leva a aumento acentuado na concentração das enzimas de função muscular (Bogin et al., 1989).

Este estudo teve o objetivo de comparar a atividade das enzimas séricas de função muscular (CK, LDH e AST) em eqüinos de diferentes categorias de atividade (atleta, tração e reprodução). 
Foram utilizados 58 eqüinos da raça Quarto de Milha (QM) e sem raça definida (SRD) divididos em três grupos, grupo 1: 20 animais atletas (cavalos e éguas com idades variadas), competidores de vaquejada; grupo 2: 20 animais (cavalos e éguas com idade entre 4 e 15 anos) destinados à reprodução - esses animais foram criados em sistema semi-intensivo, com regime alimentar constituído de pasto e ração, e mantidos sem exercício físico; grupo 3: 18 animais de tração (machos e fêmeas com idades variadas), cavalos de carroça que trabalham em média 10 horas diárias. Os eqüinos eram oriundos do município de Mossoró, encontrados no Porcino Parque Center durante um evento de vaquejada, do Haras Quatro Emes e na Feira do Bode para os grupos 1, 2 e 3, respectivamente. Todos os animais dos grupos 1 e 2 eram da raça QM, enquanto os do grupo 3 eram SRD. Foi colhida, de cada animal, uma amostra de sangue sem anticoagulante, para a obtenção do soro. Todas as amostras foram acondicionadas individualmente, identificadas e armazenadas em congelador até o momento das análises bioquímicas.

A determinação da atividade das enzimas CK, LDH e AST foi realizada utilizando kits comerciais específicos (Doles $\left.{ }^{\circledR}\right)$. A leitura das amostras foi realizada no espectrofotômetro Celm ${ }^{\circledR}$ E-225D, medindo as absorbâncias em 660, 510 e $505 \mathrm{~nm}$ para CK, LDH e AST, respectivamente. Foram seguidas rigorosamente as instruções contidas nos manuais dos kits.

Calcularam-se as médias e seus respectivos desvios-padrão para cada enzima em cada categoria eqüina. Procederam-se à análise de variância e ao teste Duncan para comparação de médias. As análises estatísticas foram realizadas com o auxílio do programa GraphPad Instat v.3.01.

As atividades séricas de CK, LDH e AST dos eqüinos das diferentes categorias estão apresentadas na Tab. 1. Os resultados das atividades séricas da $\mathrm{CK}$ no grupo 3 foram mais elevados $(\mathrm{P}<0,05)$ quando comparados com os dos outros grupos. Com relação às atividades séricas de AST, os valores dos grupos 1 e 3 foram mais altos $(\mathrm{P}<0,05)$ que os do grupo 2. As variações nas atividades séricas da enzima $\mathrm{LDH}$ encontradas entre os outros grupos não foram significantes.

Tabela 1. Média \pm desvio-padrão da atividade sérica (em U/l) das enzimas CK, LDH e AST determinadas em eqüinos de diferentes categorias de atividade, nos grupos 1 (atletas), 2 (de reprodução) e 3 (de tração)

\begin{tabular}{cccc}
\hline Grupo & $\begin{array}{c}\mathrm{CK} \\
(\mathrm{em} \mathrm{U} / 1)\end{array}$ & $\begin{array}{c}\mathrm{LDH} \\
(\mathrm{em} \mathrm{U} / \mathrm{l})\end{array}$ & $\begin{array}{c}\text { AST } \\
(\mathrm{em} \mathrm{U} / \mathrm{l})\end{array}$ \\
\hline $\begin{array}{c}1 \\
\mathrm{n}=20)\end{array}$ & $80,2 \pm 10,7 \mathrm{a}$ & $102,5 \pm 30,0$ & $56,8 \pm 20,9 \mathrm{a}$ \\
$\begin{array}{c}\mathrm{n}=20) \\
3\end{array}$ & $83,9 \pm 13,9 \mathrm{a}$ & $98,6 \pm 34,4$ & $33,0 \pm 13,1 \mathrm{~b}$ \\
$(\mathrm{n}=18)$ & $94,4 \pm 16,0 \mathrm{~b}$ & $112,8 \pm 32,3$ & $50,1 \pm 19,2 \mathrm{a}$ \\
\hline
\end{tabular}

Valores com letras diferentes em cada enzima diferem entre si ( $\mathrm{P}>0,05$; teste Duncan).

Grupo 1: animais atletas; grupo 2: animais de reprodução; grupo 3: animais de tração.

Os eqüinos de tração tiveram valores mais elevados para CK e AST do que os de reprodução, enquanto os de vaquejada apresentaram apenas a AST mais elevada. Tal fato deve-se, provavelmente, ao tipo de atividade, que é mais intensa nos cavalos de carroceiros e intermediária nos de vaquejada. Esse fato provavelmente deve-se a adaptações bioquímicas na musculatura promovidas pelo nível de atividade física. De fato, foi verificado que o treinamento de eqüinos para corridas é responsável por aumento nas atividades de citrato sintetase, hexoquinase e 3-OH-acetil-CoA dehidrogenase (Cardinet III, 1997). Além disso, há diferenças nas capacidades oxidativa e glicolítica em diferentes porções do mesmo músculo e entre diferentes tipos de fibras musculares (Sewell et al., 1994).

Acredita-se que ocorram alterações nas concentrações das enzimas de origem muscular em resposta ao treinamento e exercícios (Rose et al., 1983; Duncan e Prasse, 1986; Freestone et al., 1989; Cardinet III, 1997; Harris et al., 1998). 
O efeito do exercício sobre as atividades enzimáticas de função muscular tem sido estudado em eqüinos em momentos antes e após atividade física. Assim, a permeabilidade do sarcolema aumenta durante o exercício, e a CK e AST podem escoar para o plasma (Valberg, 1996). Quando o período de duração do exercício é mantido constante, a intensidade do exercício determina o aumento na concentração de CK (Harris et al., 1998). Um programa de treinamento adequado, que se ajusta ao condicionamento físico do eqüino, não leva a um aumento acentuado na concentração das enzimas de função muscular (Bogin et al., 1989).
Concluindo, os valores de função bioquímica muscular nos eqüinos variaram segundo o tipo de atividade física à qual eram submetidos. Dessa forma, deve-se levar em consideração o nível de atividade ao qual o eqüino esteja submetido para melhor interpretação dos resultados das atividades séricas de CK e AST.

Palavras-chave: eqüino, função muscular, creatina fosfoquinase, lactato desidrogenase, aspartato aminotransferase

\begin{abstract}
The creatine kinase (CK), lactate dehydrogenase (LDH), and aspartate aminotransferase (AST) seric activities in horses of different activity classes (athlete, traction, and reproduction), were compared. Fifty-eight horses were alloted into three groups - group 1 with 20 athletes, "vaquejada" competitors; group 2 with 20 breeding horses; and group 3 with 18 draft horses, averaging 10 working hours daily. The average values for CK serum activity were 80.2, 83.9, and 94.4 U/l in groups 1, 2, and 3, respectively. Result of group 3 was significantly different from the other groups. The averages values for LDH were 102.5, 98.6, and 112.8 U/l in groups 1, 2, and 3, respectively, with no statistical difference between groups. The AST averages were 56.8, 33.0, and 50.1 U/l in groups 1, 2, and 3, respectively, with group 2 significantly differing from the others. Clinical biochemistry values of muscular function in horses varied according to activity category.
\end{abstract}

Keywords: equine, muscular function, creatine kinase, lactate dehydrogenase, aspartate aminotransferase

\section{REFERÊNCIAS BIBLIOGRÁFICAS}

BEECH, J. Equine muscle disorders 1: Chronic intermittent rhabdomyolysis. Equine Vet. Ed., v.12, p.163-167, 2000a.

$\mathrm{BEECH}$, J. Equine muscle disorders 2. Equine Vet. Ed., v.12, p.208-213, 2000 b.

BOGIN, E.; OTTO, F.; IBAÑEZ, A. Patologia clínica veterinária. Assunción: Maknografic, 1989. 192p.

CARDINET III, G.H. Skeletal muscle function. In: KANEKO, J.J.; HARVEY, J.W.; BRUSS, M.L. Clinical biochemistry of domestic animals. 5.ed. San Diego: Academic, 1997.

DUNCAN, J.R.; PRASSE, K.W. Veterinary laboratory medicine, clinical pathology. 2.ed. Ames: Iowa State University, 1986. 285p.

FREESTONE, J.F.; KAMERLING, B.S.; $\mathrm{CHURCH}, \mathrm{G}$. Exercise induced changes in creatine kinase and aspartate aminotrasferase activites in the horse: effects of conditioning, exercise tests and acepromazine. J. Equine Vet. Sci., v.9, p.275-280, 1989.

HARRIS, P.A.; MARLIN, D.J.; GRAY, J. Plasma aspartate aminotransferase and creatine kinase activities in thoroughbred racehorses in relation to age, sex, exercice and training. Vet. J., v.155, p.295-304, 1998.

ROSE, R.J.; HODGSON, D.R.; SAMPSON, D. Changes in plasma biochemistry in horses competing in a $160 \mathrm{~km}$ endurance ride. Aust. Vet. J., v.60, p.101-1105, 1983.

SEWELL, D.A.; HARRIS, R.C.; MARLIN, D.J. Skeletal muscle characteristics in 2 year-old race-trained thoroughbred horses. Comp. Biochem. Physiol., v.108A, p.87-96, 1994.

VALBERG, S.J. Muscular causes of exercise intolerance in horses. Vet. Clin. N. Am.: Equine Pract., v.12, p.495-515, 1996. 